Rapid Reviews COVID-19

\title{
Reviews of "How early into the outbreak can surveillance of SARS-CoV-2 in wastewater tell us?"
}

Han Xia ${ }^{1}$, Shivranjani Moharir ${ }^{2}$, Rakesh Mishra ${ }^{3}$

${ }^{1}$ Wuhan Institute of Virology, Chinese Academy of Sciences, Key laboratory of special pathogens and biosafety,

${ }^{2}$ CCMB: Centre for Cellular and Molecular Biology CSIR,

${ }^{3}$ CSIR-Centre for Cellular and Molecular Biology, India

Published on: Oct 02, 2020

DOI: $10.1162 / 2 \mathrm{e} 3983 f 5 . a 229744 \mathrm{c}$

License: Creative Commons Attribution 4.0 International License (CC-BY 4.0). 
To read the original manuscript, click the link above.

Summary of Reviews: This study explores wastewater surveillance for monitoring COVID-19 outbreaks and identifies the case prevalence required for detecting infection in a hospital setting. The claims are somewhat supported by the data presented, but confounding variables limit policy applications.

Reviewer 1 (Han Xia)

Reviewer 2 (Shivranjani Moharir, Rakesh Mishra) |

\section{RR:C19 Strength of Evidence Scale Key}

प्रमप = Misleading

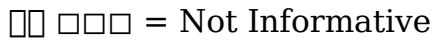

प्रा पि = Potentially Informative

प्र०प्र = Reliable

प्राप्रा = Strong

To read the reviews, click the links below. 